\title{
GUANOSINE 5'-O-(2-THIODIPHOSPHATE) AS A COMPETITIVE INHIBITOR OF GTP IN HORMONE OR CHOLERA TOXIN-STIMULATED PANCREATIC ADENYLATE CYCLASE
}

\author{
M. SVOBODA, J. FURNELLE, F. ECKSTEIN ${ }^{+}$and J. CHRISTOPHE* \\ Department of Biochemistry and Nutrition, School of Medicine, Université Libre de Bruxelles, Boulevard de Waterloo 115. \\ B-1000 Brussels, Belgium and ${ }^{+}$Max.Planck-Institut für Experimentelle Medizin, Abteilung Chemie, D-3400 Göttingen, FRG
}

Received 14 November 1979

\section{Introduction}

The hormone-sensitive adenylate cyclase of many eucaryotic cells is controlled by the presence of guanyl nucleotides (reviewed $[1,2]$ ). The catalytic subunit is highly active in the presence of a guanyl nucleotide triphosphate but is inactive or poorly active in the presence of GDP [3-5]. Hormones act in altering the configuration of the system to facilitate the access of the activating nucleotide triphosphate [4-7]. The switch-off mechanism of adenylate cyclase activity consists of the hydrolysis of the guanyl nucleotide triphosphate by the GTPase present in the system and can be inhibited by a cholera toxin pretreatment $[8-10]$.

According to this mechanism, GDP should be an antagonist of GTP action on adenylate cyclase. However GDP itself cannot be tested since it is rapidly phosphorylated by the ATP-regenerating system present in the adenylate cyclase assay medium. We decided to use GDPßS, a GDP analog which is only slowly phosphorylated by the regenerating system [11]. The system tested was the adenylate cyclase present in semi-purified rat pancreatic plasma membranes. This system consists of at least 4 functionally distinct components: the catalytic unit; hormone receptors; and two classes of guanyl nucleotide sites, the first one $\mathrm{N}_{1}$ allowing the transduction of the hormone-generated signal and the second one $\mathrm{N}_{2}$ con-

Abbreviations: GDP $\beta S$, guanosine 5'-O-(2-thiodiphosphate); Hepes, $N$-2-hydroxyethylpiperazine-2 $V^{+}-2$-ethanesulfonic acid; TES, $N$-tris(hydroxymethyl)methyl-2-aminoethane sulfonic acid; CCK -8, C-terminal octapeptide of cholecystokininpancreozymin (CCK-PZ); VIP, vasoactive intestinal peptide

* To whom correspondence should be addressed trolling the activity of the catalytic unit [12]. This system is activated by the synergetic action of GTP and of a peptide belonging to either the secretin or the cholecystokinin-pancreozymin (CCK-PZ) family of hormones.

In both hormone-activated native pancreatic plasma membranes and in cholera toxin pretreated membranes GDP $\beta$ S proved indeed to be an antagonist of GTP activation of adenylate cyclase. The apparent affinity of GDP $\beta$ S and GTP for the native system was 6-7-fold higher in the presence of CCK-8 than in the presence of secretin. This suggests that:

(i) The number of CCK-8 receptors in pancreatic plasma membranes was higher than the number of secretin receptors; or

(ii) Guanyl nucleotide binding sites directly associated with CCK- 8 and secretin receptors were distinct.

\section{Materials and methods}

Guanosine 5'-O-(2-thiodiphosphate) was synthesized by Dr Eckstein (Max-Planck Institut für Experimentelle Medizin, Göttingen). Synthetic C-terminal octapeptide of cholecystokinin-pancreozymin (CCK-8) and natural porcine secretin were generous gifts from Dr Lucania (Squibb Institute for Medical Research, Princeton, NJ) and Dr Mutt (Karolinska Institutet, Stockholm), respectively, $\left[\alpha \cdot{ }^{32} \mathrm{P}\right] \mathrm{ATP}$ and cyclic $\left[8 \cdot{ }^{3} \mathrm{H}\right] \mathrm{AMP}$ were obtained from the Radiochemical Centre (Amersham, Bucks). Cholera toxin was from Schwarz/Mann (Orangeburg, NY). Guanosine $5^{\prime}-(\beta-\gamma$-imido)triphosphate and GTP were provided by Boehringer (Mannheim). ATP, phospho(enol)pyruvate, pyruvate kinase, and cyclic AMP were purchased 
from Sigma Chemical Co. (St Louis, MO). ATP was purified by 3 successive chromatographies [13]. All other reagents were commercial preparations of analytical grade.

Rat pancreatic plasma membranes were prepared as in [14] and stored in liquid nitrogen until use.

The cholera toxin pretreatment of these membranes was that developed for turkey erythrocytes [9]. Briefly, cholera toxin was preactivated at $37^{\circ} \mathrm{C}$ in $1.5 \mathrm{ml}$ cytosol of packed human erythrocytes. After 15 min incubation, an equal volume of pancreatic membranes suspended in $20 \mathrm{mM}$ Hepes buffer ( $\mathrm{pH} 7.4$ ) containing $2 \mathrm{mM} \mathrm{NAD}^{+}, 4 \mathrm{mM} \mathrm{ATP}, 10 \mathrm{mM}$ phospho(enol)pyruvate, and $16 \mathrm{U}$ pyruvate kinase $/ \mathrm{ml}$ was added. Membrane protection was insured by the presence of soybean trypsin inhibitor (final conc. $0.05 \mathrm{mg} / \mathrm{ml}$ ), a suspension of hepatic phospholipids $(0.2 \mathrm{mg} / \mathrm{ml})$ and by decreasing to $30^{\circ} \mathrm{C}$. The final toxin conc. was $30 \mu \mathrm{g} / \mathrm{ml}$. After $5 \mathrm{~min}$ at $30^{\circ} \mathrm{C}$ the toxin treatment of plasma membranes was stopped by adding $5 \mathrm{ml}$ of ice-cold washing buffer composed of $10 \mathrm{mM}$ TES ( $\mathrm{pH} 7.4$ ), $30 \mathrm{mM} \mathrm{NaCl}, 0.1 \mathrm{mM}$ dithioerythritol and $0.5 \mathrm{mM}$ EDTA. After immediate centrifugation at $50000 \times \mathrm{g}$ for $10 \mathrm{~min}$ at $2^{\circ} \mathrm{C}$, the pellet was rinsed out, resuspended in $5 \mathrm{ml}$ washing buffer and centrifuged again. This washing procedure was repeated 3 times. Washed membranes were finally homogenized in a $10 \mathrm{mM}$ TES buffer $(\mathrm{pH} 7.4)$ containing $30 \mathrm{mM} \mathrm{NaCl}, 0.2 \mathrm{mM}$ EDTA, $0.1 \mathrm{mM} \mathrm{MgCl} 2$, $0.1 \mathrm{mM}$ dithioerythritol, $0.05 \mathrm{mg} / \mathrm{ml}$ soybean trypsin inhibitor, and $0.2 \mathrm{mg} / \mathrm{ml}$ phospholipid suspension, to obtain final membrane protein conc. $0.5-1.0 \mathrm{mg} / \mathrm{ml}$. Control membranes underwent the complete procedure without cholera toxin addition.

The adenylate cyclase activity was measured at $37^{\circ} \mathrm{C}$ in a medium containing $30 \mathrm{mM}$ Tris $-\mathrm{HCl}$, $5 \mathrm{mM} \mathrm{MgCl}, 0.5 \mathrm{mM}$ EGTA, $1 \mathrm{mM}$ theophylline, $1 \mathrm{mM}$ cyclic AMP, $0.5 \mathrm{mM}\left[\alpha \cdot{ }^{32} \mathrm{P}\right]$ ATP $(1-2 \mu \mathrm{Ci})$ test), and an ATP regenerating system made of $10 \mathrm{mM}$ phospho(enol)pyruvate and pyruvate kinase $(15 \mathrm{U} / \mathrm{ml})$. The $\mathrm{pH}$ was adjusted to 7.4 at $25^{\circ} \mathrm{C}$. The reaction was initiated by addition of membranes and was conducted in $60 \mu \mathrm{l}$. The reaction was stopped after $7 \mathrm{~min}$ incubation by addition of $0.5 \mathrm{ml} 0.1 \%$ sodium dodecylsulfate solution containing $1 \mathrm{mM}$ ATP and $0.5 \mathrm{mM}$ cyclic $\left[8 \cdot{ }^{3} \mathrm{H}\right] \mathrm{AMP}(\sim 20000 \mathrm{cpm})$. The isolation of cyclic $\left[{ }^{32} \mathrm{P}\right] \mathrm{AMP}$ formed during incubation was achieved by sequential chromatography on columns of Dowex 50 WX-8 and aluminium oxide [15]. Membrane protein was determined by the
Lowry method [16] using bovine serum albumin as standard,

\section{Results}

Native pancreatic adenylate cyclase was strongly stimulated by the two gastrointestinal peptides CCK -8 and secretin provided that GTP was present in the incubation medium (table 1, fig.2). GTP alone was a very weak activator of native pancreatic adenylate cyclase so that the direct interaction of GDP $\beta S$ with GTP could not be tested, By contrast, a cholera toxin pretreatment allowed a selective and 14 fold increase in GTP efficacy (table 1) in that GTP alone, when used at optimal concentration [17], now allowed $69 \%$ of the maximal activity observed in the combined presence of GTP and $1 \mu \mathrm{M} \mathrm{CCK}-8$, as compared to $5 \%$ in untreated control membranes. Using these experimental conditions, the dose-response curves of GTP activation illustrated in fig. 1 indicate that GDPßS was a competitive inhibitor of GTP. The app. $K_{\mathrm{a}}$ of GTP was $0.10 \mu \mathrm{M}$ and the $K_{\mathrm{i}}$ of GDP $\beta$ S was $0.60 \mu \mathrm{M}$. In another membrane preparation the corresponding values were 0.15 and $0.30 \mu \mathrm{M}$ (table 2).

Having established the status of GDP $\beta$ S as a competitive inhibitor of GDP on cholera toxin-treated membranes, we next studied the action of GDP $\beta$ S on hormone-stimulated native adenylate cyclase (fig.2). In the absence of added GTP, GDP $\beta$ S inhibited the significant stimulation of pancreatic membranes by

Table 1

Effects of cholera toxin pretreatment of rat pancreatic plasma membranes on adenylate cyclase activity

\begin{tabular}{lrrr}
\hline Additions & \multicolumn{2}{l}{ Membrane pretreatment } \\
\cline { 2 - 3 } & \multicolumn{2}{c}{ Control } & Cholera toxin \\
\hline None & $14 \pm 2$ & $128 \pm 23$ \\
$30 \mu \mathrm{M} \mathrm{GTP}$ & $37 \pm 8$ & $729 \pm 198$ \\
$0.3 \mu \mathrm{M} \mathrm{CCK}-8+30 \mu \mathrm{M} \mathrm{GTP}$ & $813 \pm 202$ & $1061 \pm 109$ \\
$10 \mathrm{mM} \mathrm{NaF}$ & $932 \pm 129$ & $315 \pm 97$ \\
\hline
\end{tabular}

Plasma membranes were pretreated in the cytosol of human erythrocytes and in the absence or in the presence of $30 \mu \mathrm{g}$ cholera toxin $/ \mathrm{ml}$, as in section 2 . The adenylate cyclase activity of washed membranes was assayed in the standard medium or in the presence of $10 \mathrm{mM} \mathrm{NaF}$ or $30 \mu \mathrm{M}$ GTP (with or without $0.3 \mu \mathrm{M} \mathrm{CCK}-8$ ). The data are expressed as pmol cyclic AMP formed, $\min ^{-1}$, mg protein ${ }^{-1}$. Means \pm SEM of 4 different preparations 

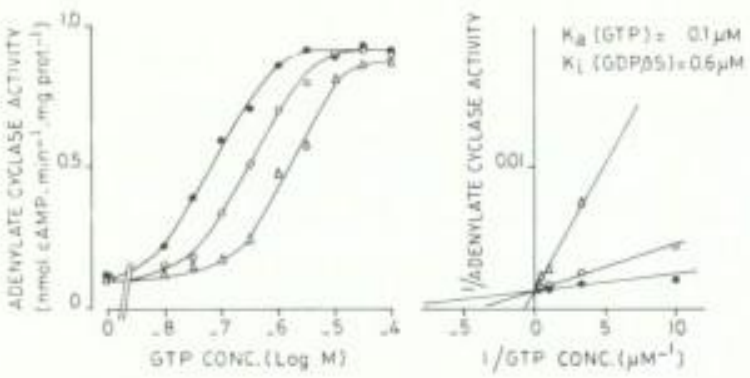

Fig.1. Competitive inhibition by GDPpS of GTP activation of adenylate cyclase activity in pancreatic plasma membranes pretreated with choleta toxin. Rat pancreatic plasma membranes were pretreated with cholera toxin $(30 \mu \mathrm{g} /$ test $)$ as in section 2 . These membranes were then incubated with increasing concentrations of GTP in the adenylate cyclase assay medium containing highly purified ATP, and in the absence $(\bullet)$ or presence of $1 \mu \mathrm{M} \mathrm{GDP} \beta S(0)$ or $10 \mu \mathrm{M}$ GDP $\beta S(\Delta)$. Dose-response curves of adenylate cyclase activation in the left panel are presented as Lineweaver-Burk plots in the right panel. In the latter representation, all values were corrected for basal adenylate cyclase activity. Results are the means of duplicate determination. In this experiment, the $K_{\mathrm{a}}$ of GTP was $0.1 \mu \mathrm{M}$ and the $K_{\mathrm{i}}$ of GDP $\beta \mathrm{S}$ was $0.6 \mu \mathrm{M}$. In another experiment with a distinct batch of pancreatic plasma membranes the values of $K_{\mathrm{a}}$ and $K_{\mathrm{i}}$ were, $0.15 \mu \mathrm{M}$ and $0.3 \mu \mathrm{M}$, respectively.

CCK-8 while slightly enhancing the secretin-dependent activation (fig. 2 , middle panel). In the presence of added GTP, increasing GDP $\beta$ S concentration caused a progressive inhibition of hormone + GTP activation.
There were again differences between CCK-8 and secretin-dependent activation in that:

(i) GDP $\beta$ S inhibited CCK-8 stimulation more completely than secretin activation (fig.2, left panel);

(ii) The $I_{50}$ of GDP $\beta S$ inhibition $(2.2 \pm 2 \mu \mathrm{M} ; n=3)$ for CCK-8+GTP stimulation was lower than that for secretin + GTP stimulation $(8 \pm 2 \mu \mathrm{M})$ (fig. 2 , right panel).

The latter phenomenon was further investigated by determining the response of CCK- 8 and secretinstimulated pancreatic adenylate cyclase to increasing concentrations of GTP in the presence of two GDP $\beta$ S concentrations (fig. 3 ). In the presence of both secretin and CCK -8 , the inhibition by GDP $\beta$ S was competitive

Table 2

CCK-8, secretin, and cholera toxin pretreatment on the affinity of GTP and GDP $\beta$ S for regulation of adenylate cyclase activity in rat pancreatic plasma membranes

\begin{tabular}{|c|c|c|c|}
\hline $\begin{array}{l}\text { Membrane } \\
\text { pretreatment }\end{array}$ & $\begin{array}{l}\text { Hormone } \\
\text { addition }\end{array}$ & $\begin{array}{l}K_{\mathrm{a}} \text { for GTP } \\
(\mu \mathrm{M})\end{array}$ & $\begin{array}{l}K_{\mathrm{i}} \text { for GDP } \beta \mathrm{S} \\
(\mu \mathrm{M})\end{array}$ \\
\hline Cholera toxin & None & $0.15-0.10$ & $0.3-0.6$ \\
\hline Native & CCK-8 & $0.043=0.006$ & $0.5 \neq 0.1$ \\
\hline Native & Secretin & $0.28=0.04$ & $3.2=0.4$ \\
\hline
\end{tabular}

The apparent affinity constants $K_{\mathrm{a}}$ and $K_{\mathrm{i}}$ for GTP and GDP $\beta$, respectively, were calculated for cholera toxin pretreated membranes from the 2 expt in fig.1. The same constants in hormone-stimulated native membranes were calculated from data in fig. 3 (mean \pm SEM of 4 different preparations)
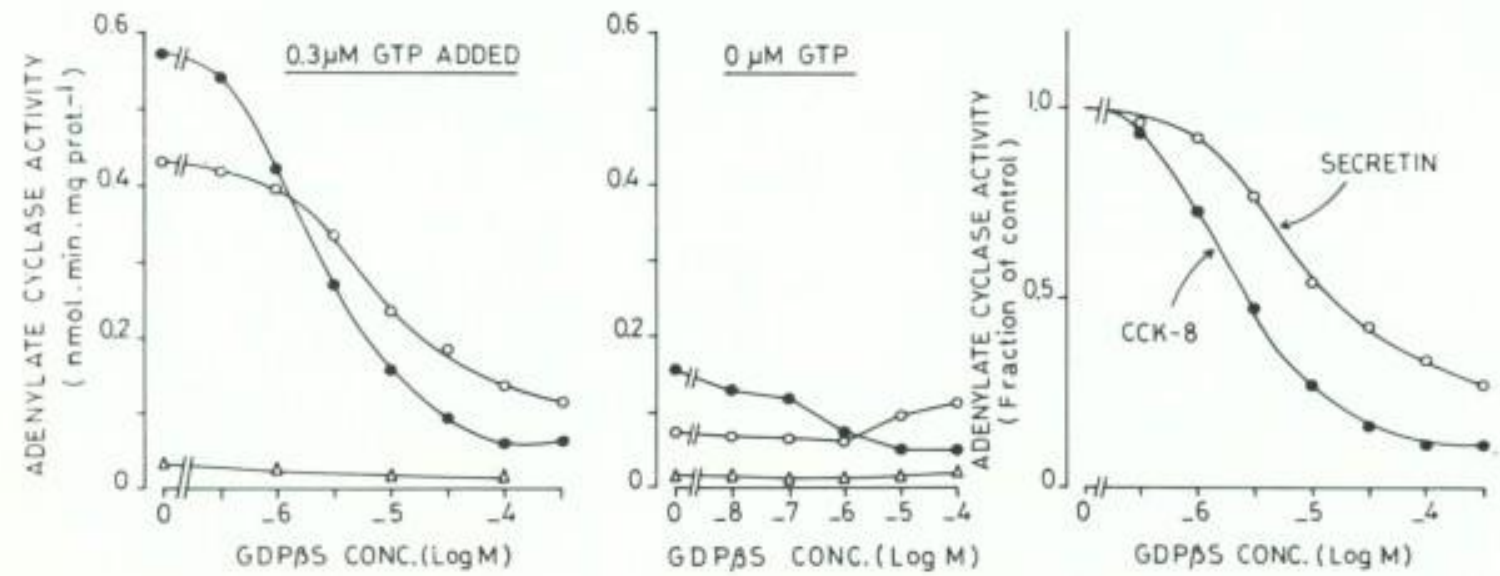

Fig.2. Effects of GDP $\beta$ S on CCK-8 and secretin-stimulated pancreatic adenylate cyclase activity. Native pancreatic plasma membranes were incubated in the adenylate cyclase medium without $(\Delta)$ or with $1 \mu \mathrm{M} \mathrm{CCK}-8(\bullet)$ or $1 \mu \mathrm{M}$ secretin $(\circ)$, and in the presence of increasing concentrations of GDP $\beta$ S. The experiment was performed in the presence (left panel) or absence (middle panel) of exogenous GTP, at $0.3 \mu \mathrm{M}$. In the right panel, adenylate cyclase activity, in the presence of $0.3 \mu \mathrm{M}$ GTP is expressed as fraction of control activity in the absence of GDP $\beta$ S. All values are the mean of 3 expt. 


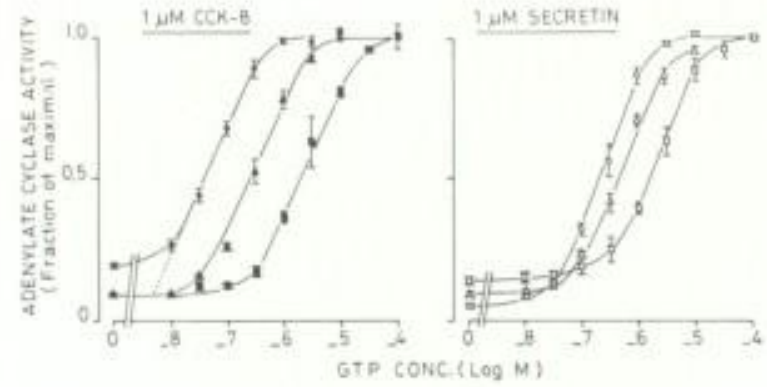

Fig.3. Effect of GDP $\rho$ S on GTP activation of pancreatic adenylate cyclase activity in the presence of CCK- 8 or secretin. Rat pancreatic plasma membranes were incubated in the presence of increasing concentrations of GTP, and with or without $1 \mu \mathrm{M}$ CCK -8 (left panel) or $1 \mu \mathrm{M}$ secretin (right

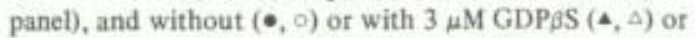
$30 \mu \mathrm{M}$ GDP $\beta \mathrm{S}(\boldsymbol{\bullet}, \mathrm{D})$. Results are means \pm SEM of experiments performed in duplicate without GDPBS $(n=4)$ or with $3 \mu \mathrm{M} \operatorname{GDP} \beta \mathrm{S}(n=4)$ or $30 \mu \mathrm{M} \operatorname{GDP} \beta \mathrm{S}(n=3)$.

with regard to GTP activation. In the presence of CCK-8, the adenylate cyclase activity recorded in the absence of added GTP was considered as due to endogenous GTP-like material on the basis of the evidence in fig. 2 (middle panel). The apparent affinity of GTP action, extrapolated from dose-effect curves as shown in fig. 3 (left panel), was significantly greater in the presence of CCK $-8\left(K_{\mathrm{a}} 0.04 \mu \mathrm{M}\right)$ than in the presence of secretin $\left(K_{\mathrm{a}} 0.28 \mu \mathrm{M}\right)$.

\section{Discussion}

Guanyl nucleotides activate pancreatic adenylate cyclase in synergy with CCK-8 or secretin [17]. CCK-8 alone produces however a significant activation (30-50\% of maximal) whereas secretin alone is 3-times less efficient [17]. This is puzzling since a peptide hormone alone should not activate an adenylate cyclase system operating through a hormone-nucleotide interdependent mechanism [2]. Two explanations are conceivable:

(i) Component(s) in our adenylate cyclase assay medium, i.a. ATP or plasma membranes, contained enough GTP-like material for CCK-8 but not for secretin activation;

(ii) CCK-8 alone was capable to activate adenylate cyclase by a mechanism distinct from the hormone-nucleotide dependent system.

The utilization of highly purified ATP [13] as substrate was only capable to reduce the activation by secretin alone or CCK- 8 alone (fig. 2 , middle panel). The present observation that low concentrations of GDP $\beta$ S inhibited the residual activation by CCK. 8 alone (fig. 2 , middle panel) was thus required to demonstrate the presence of residual GTP-like material in the assay medium.

That CCK 8 alone was more efficient than secretin alone on pancreatic adenylate cyclase implied also that the action of CCK-8 was more sensitive to GTP, In this respect we made a wrong assumption in [17] when estimating the $K_{\mathrm{a}}$ of GTP after subtracting the activity observed in the absence of added GTP from dose-response curves of hormone-stimulated pancreatic adenylate cyclase. Similar values of $K_{\mathrm{a}}$ for GTP were then obtained in the presence of CCK-8 or secretin. This method was incorrect since we now know that the hormone-dependent activity observed in the absence of added GTP was due in fact to the presence of endogenous GTP-like material and cannot, therefore, be subtracted. The present data, based on the use of GDP $\beta$ S, clearly demonstrate that the app. $K_{\mathrm{a}}$ of GTP for adenylate cyclase regulation was in fact 7 times higher in the presence of CCK. 8 than in the presence of secretin (table 2).

The indication that pancreatic adenylate cyclase possess two functionally distinct guanyl nucleotide sites, one $\mathrm{N}_{1}$ indispensable for hormone coupling and another one $\mathrm{N}_{2}$ promoting adenylate cyclase activity [12], may provide a clue for such a discrepancy. Hepatic plasma membranes [18] also contain functionally distinct guanyl nucleotide sites involved, respectively, in the regulation of hormone binding $\left(\mathrm{N}_{1}\right.$ sites $)$ and adenylate cyclase activity $\left(\mathrm{N}_{2}\right.$ sites). In these membranes, GDP prevents the occupancy of $\mathrm{N}_{2}$ by GTP and the resulting activation of the catalytical subunit. In contrast, GDP and GTP promote the coupling of the glucagon-receptor complex to adenylate cyclase with similar efficacy at $N_{1}$ sites [19]. In pigeon erythrocytes, only one guanyl nucleotide binding protein related to adenylate cyclase activity has been isolated $[20,21]$ but it is possible that this single protein displays changeable characteristics when promoting distinct regulatory events or that it contains several guanyl nucleotide binding sites.

The present data showed that the requirement for GTP of CCK-8 activation of pancreatic adenylate cyclase was 7-fold lower than for secretin activation. Considering that both hormones finally activate the 
same catalytic unit associated with the same guanyl nucleotide regulatory site $\mathrm{N}_{2}[12]$, the difference in GTP action may be due to those guanyl nucleotide sites $\mathrm{N}_{1}$ linked to hormone receptors. If the activa. tion-deactivation process operating at $\mathrm{N}_{2}$ sites, at saturating hormone concentration, is indeed controlled by the affinity of function $N_{1}$ regulatory sites for nucleotides, the present data could be explained by two mechanisms:

(i) The guanyl nucleotide regulatory protein $\mathrm{N}_{1}$ associated with CCK-receptors differs from that associated with secretin receptors;

(ii) CCK receptors [22] are in excess over secretin (VIP) receptors (Robberecht et al., unpublished results) and catalytic subunits.

The occupancy of a given fraction of $\mathrm{N}_{1}$ by GTP would allow the formation of more (CCK-8-receptor) $\mathrm{N}_{1}$-GTP than (secretin-receptor) $-\mathrm{N}_{1}$-GTP complexes. Despite the identical intrinsic affinity of GTP for all nucleotide regulatory binding sites $\mathrm{N}_{1}$, the apparent affinity of GTP for CCK-8-dependent stimulation would then be higher than that for secretin stimulation and this might provide a biochemical role for 'spare' CCK-8 receptors in vitro [23].

\section{Acknowledgements}

Aided by grant 20,403 from the Fonds de la Recherche Scientifique Médicale (Belgium) and grant RO-IAM-17010 from the National Institutes of Health (USA).

\section{References}

[1] Helmreich, E. J. M., Zenner, H. P., Pfeuffer, T. and Cori, C. F. (1976) Curr. Top, Cell. Reg. 10, 59-67.

[2] Rodbell, M. (1978) in: Molecular Biology and Pharmacology of Cyclic Nucleotides (Folco, G. and Paoletti, R. eds) pp, 1-12, Elsevier/North-Holland, Amsterdam, New York.

[3] Blume, A. J. and Foster, C. J. (1976) J. Biol. Chem. 251, 3399-3404.

[4] Rendell, M. S., Rodbell, M. and Berman, M. (1977) J. Biol. Chem. 252, 7909-7912.

[5] Cassel, D. and Selinger, Z. (1978) Proc. Natl. Acad. Sci. USA 75, $4155-4159$.

[6] Cassel, D. and Selinger, Z. (1977) J. Cyclic Nucl. Res. $3,11-12$.

[7] Svoboda, M. and Christophe, J. (1979) J. Cyclic Nucl. Res. (in press).

[8] Cassel, D. and Selinger, Z. (1976) Biochim. Biophys. Acta 452, 538-551.

[9] Cassel, D. and Selinger, Z. (1977) Proc. Natl. Acad. Sci. USA 74, 3307-3311.

[10] Lambert, M., Svoboda, M. and Christophe, J. (1979) FEBS Lett. 99, 303-307.

[11] Eckstein, F., Cassel, D., Levkovitz, H., Lowe, M. and Selinger, Z. (1980) J. Biol. Chem. in press.

[12] Svoboda, M., Robberecht, P. and Christophe, J. (1978) FEBS Lett. 92, 351-356.

[13] Kimura, N. and Nagata, N. (1977) J. Biol. Chem. 252, $3829-3835$.

[14] Svoboda, M., Robberecht, P., Camus, J., DeschodtLanckman, M. and Christophe, J. (1976) Eur. J. Biochem. 69, 185-193.

[15] Salomon, Y., Londos, C. and Rodbell, M. (1974) Anal. Biochem. 58, 541-548.

[16] Lowry, O. H., Rosebrough, N. J., Farr, A. L. and Randall, R. J. (1951) J. Biol. Chem. 193, 265-275.

[17] Svoboda, M., Robberecht, P., Camus, J,, DeschodtLanckman, M. and Christophe, J. (1978) Eur. J. Biochem. 83, 287-297.

[18] Lad, P. M., Welton, A. F, and Rodbell, M. (1977) J. Biol. Chem. 252, 5942-5946.

[19] Iyengar, R, and Birnbaumer, L. (1979) Proc. Natl. Acad. Sci. USA 76, 3189-3193.

[20] Pfeuffer, T. (1977) J. Biol. Chem. 252, 7224-7234.

[21] Cassel, D. and Pfeuffer, T. (1978) Proc. Natl. Acad. Sci. USA 75, 2669-2673.

[22] Deschodt-Lanckman, M., Robberecht, P., Camus, J. and Christophe, J. (1978) Eur. J. Biochem. 91, 21-29.

[23] Freychet, P. (1976) Diabetologia 12, 83-100. 